\title{
Avaliação de desempenho docente no Brasil: desvelando concepções e tendências
}

Danielle Xabregas Pamplona Nogueira Girlene Ribeiro de Jesus Shirleide Pereira da Silva Cruz Universidade de Brasília

\section{Resumo}

Este trabalho tem como objetivo evidenciar as principais concepções e tendências dos sistemas de avaliação de desempenho docente nas redes estaduais de educação básica no Brasil. A discussão do tema tratou da relação entre avaliação, responsabilização e desenvolvimento profissional, bem como das concepções que orientam os processos avaliativos de desempenho docente. As análises do levantamento realizado a partir das informações disponíveis nos sítios das 27 Secretarias Estaduais de Educação revelaram que, nos estados brasileiros, a tendência predominante nas políticas de avaliação docente se dá na perspectiva da responsabilização, na maioria das vezes se utilizando dos resultados de avaliações do desempenho de alunos, que se distanciam dos pressupostos que orientam o processo de desenvolvimento profissional docente.

Palavras-chave: Avaliação de sistemas. Responsabilização. Avaliação do desempenho docente. 


\section{Teacher performance evaluation in Brazil: revealing concepts and trends}

The aim of this article is to show the main conceptions and trends of teaching performance evaluation systems in state-level basic education school networks in Brazil. The discussion considers the relationship between evaluation, accountability and professional development. The analysis of the survey in the 27 websites of the state departments of education revealed that, in the Brazilian states, the prevailing trend in policies of teacher evaluation takes the perspective of accountability, in most cases, using the results of students' performance evaluations, quite a deviation from the assumptions that guide the process of teacher professional development.

Keywords: Systems evaluation. Accountability. Teachers' performance evaluation.

\section{Evaluación del desempeño docente en Brasil: conceptos y tendencias}

El presente artículo tiene como objetivo revelar las principales tendencias y concepciones de los sistemas de evaluación del desempeño en las redes públicas de educación básica en Brasil. El tema de la discusión trataba de la relación entre la evaluación, rendición de cuentas y el desarrollo profesional. El análisis de los sitios de los 27 departamentos estatales de educación reveló que, en los estados de Brasil, la tendencia predominante en las políticas de evaluación docente adopta la perspectiva de la rendición de cuentas, en la mayoría de los casos, utilizando los resultados de las evaluaciones de desempeño de los estudiantes que se alejan del proceso de desarrollo profesional docente.

Palabras clave: Evaluación del desempeño docente. Rendición de cuentas. Desarrollo profesional. 


\section{Introdução}

De acordo com Jesus (2007), a avaliação do desempenho docente sempre fez parte do cotidiano desse profissional. Nesse contexto, a avaliação pode acontecer de forma implícita ou informal, ser realizada pelo próprio docente, pelo feedback dos alunos ou outros profissionais da educação.

Apesar da presença constante da avaliação na atuação do profissional docente, o referido autor afirma que os professores mostram-se muito resistentes a todas as propostas que visem à avaliação do seu desempenho, o que gera um paradoxo: os professores são os profissionais que mais utilizam a avaliação como prática do seu trabalho, mas são muito resistentes à sua própria avaliação.

Como justificativa para este paradoxo, Saul (2007) cita dois fatores geradores. 0 primeiro considera que os professores compreendem a sua avaliação como um instrumento de controle ou de punição, em contraposição à ideia de desenvolvimento profissional. 0 segundo se refere à não compreensão do processo avaliativo por avaliadores e avaliados.

Diante disso, este artigo tem como objetivo evidenciar as principais tendências e concepções avaliativas dos sistemas de avaliação de desempenho docente nas redes estaduais de educação básica no Brasil. Para tanto, tomamos como referenciais de análise a relação entre avaliação, responsabilização e desenvolvimento profissional nos sistemas de avaliação docente no Brasil, as concepções que orientam os processos avaliativos e a caracterização dos diversos sistemas de avaliação das referidas redes.

\section{Avaliação e responsabilização}

Segundo Akkari (2011), a partir do final dos anos 1980, os sistemas educacionais passam a utilizar padrões e avaliações educacionais internacionais para melhorar os seus desempenhos e implementar reformas educacionais que visavam, sobretudo, promover uma educação de qualidade.

No entanto, de acordo com Neubauer e Silveira (2009), essas ações não melhoraram os indicadores estatísticos, o que revelava que o sistema de ensino continuava fortemente excludente, com altas taxas de abandono e repetência escolar e um número pouco significativo de alunos completando a primeira etapa do ensino fundamental lquatro a seis anos de escolaridade, o que na realidade brasileira corresponderia a cinco anos, considerando o ensino fundamental de nove anos implementado pela lei 11.254/2006) além de indicar uma qualidade insatisfatória por parte dos alunos latino-americanos em testes internacionais.

Sobre as reformas educacionais, com vistas à garantia de qualidade e baseadas em padrões, Lam (2004 apud Akkari, 2011) propõe um modelo cíclico de quatro 
etapas. A primeira consiste na definição de padrões de desempenho para os estudantes. A segunda, na responsabilização das escolas e dos professores quanto às expectativas desses padrões. Em terceiro lugar, a consideração de que a avaliação em larga escala serve para acelerar as mudanças nas escolas, sendo a avaliação apoiada por políticas de incentivo às reformas. Por último, a utilização dos resultados dessa avaliação para determinar a pertinência das reformas desencadeadas e para acompanhá-las.

Nesta mesma lógica, Dee (2012) afirma que a primeira manifestação dessas reformas se deu por meio da adoção de um padrão de desempenho baseado em testes que avaliavam competências mínimas de estudantes. 0 autor destaca as críticas a esse modelo, no que se refere à expectativa de que a avaliação pudesse uniformizar as condições de aprendizagem e as características próprias dos sujeitos avaliados, gerando resultados uniformizados para condições sociais diferenciadas.

Às definições de qualidade e finalidade da avaliação pode-se acrescentar a responsabilização como elemento indutor dos processos avaliativos. Para Dee (2012), historicamente, o conceito de responsabilização surge no contexto dos relatórios de reformas educativas baseadas em padrões, na América do Norte, associado a um sistema de certificação de estudantes com testes de competências mínimas.

Segundo Brooke (2006), pode-se caracterizar três formas ou modalidades de responsabilização voltadas ao desempenho docente, as quais são diferenciadas de acordo com as instituições que as aplicam e com o comportamento exigido. A primeira forma é denominada como burocrática. Esta procura a conformidade com as normas legais ditadas pela rede de ensino na qual o professor trabalha, e este é responsabilizado pelo cumprimento das leis perante a burocracia que o contratou.

A segunda forma indica a exigência de um comportamento profissional em conformidade com as normas formais e informais estabelecidas pelos colegas de profissão. Assim, o professor é responsabilizado pela manutenção dos padrões da profissão perante seus pares.

Na terceira modalidade, a responsabilização tem como base os resultados da escola. Nela, o educador é responsabilizado perante as autoridades e o público em geral pela aprendizagem dos alunos. Além disso, as consequências, reais ou simbólicas, são associadas às medidas usadas para aferir o desempenho dos alunos.

Com esse entendimento, Neubauer e Silveira (2009) asseguram que os efeitos da responsabilização acabam por produzir novos padrões de avaliação que vão desde a divulgação dos resultados do desempenho das escolas até a elaboração de critérios de incentivos ou sanções no interior dos sistemas. Para eles, 
em geral, os sistemas de responsabilização que vêm sendo implementados, combinam as seguintes condições: a decisão, por parte dos sistemas, de divulgar os resultados relativos ao desempenho das escolas; a aplicação de testes padronizados que gerem informações sobre esse desempenho; a definição de critérios para classificar escolas a partir dos resultados obtidos nos testes aplicados le em outros procedimentos de avaliaçãol e, finalmente, a definição de critérios para a aplicação de incentivos ou sanções conforme os padrões estabelecidos. (Neubauer; Silveira, 2009, p. 106)

No que se refere aos resultados, Akkari (2011) esclarece que a obrigação destes foi operacionalizada nas políticas educativas por meio da noção de accountability. Entendida como prestação de contas, a accountability se insere em um processo de gestão para explicar as atividades realizadas e os resultados obtidos em função de objetivos predeterminados e, se necessário, fazer a ligação com os recursos (humanos, materiais e financeiros) investidos para sua realização.

De acordo com o autor, se por um lado a prestação de contas visa ajudar os atores do sistema educativo a se ajustarem de maneira contínua a um ambiente em constante evolução, instigar a tomada de decisões, prestar contas à sociedade civil sobre a gestão da escola e assumir as responsabilidades do cargo recebido, por outro, para os professores, esta exigência de resultados consiste essencialmente em uma "obrigação de atenção" aos efeitos de suas ações sobre os alunos.

Neubauer e Silveira (2009) declaram que os efeitos dessas reformas enfatizaram - papel do gestor como liderança estratégica para a eficiência e a eficácia da escola e a responsabilização da unidade escolar pelos resultados obtidos. Como consequência, no Brasil, houve o estímulo de experiências de pagamento de bônus, premiação de professores e/ou diretores pelo desempenho dos seus alunos ou de suas escolas, comprovando a efetivação da terceira etapa das reformas educacionais, conforme classificação de Lam. (2004 apud Akkari, 2011)

\section{Efeitos da responsabilização na avaliação de desempenho docente}

Partindo de análises sobre o uso previsto dos resultados das avaliações nas propostas de países da América Latina, Ravela (2003 apud Sousa, 2009) identificou duas tendências. A primeira concebe a avaliação com finalidade formativa, enquanto a segunda prevê o uso dos resultados como mecanismo para aplicação de incentivos e sanções às escolas, tendência esta apoiada por políticos economistas, sob o argumento de mobilizar profissionais e alunos a buscarem melhores desempenhos nas provas.

Seguindo essa classificação, Sousa (2009) evidencia que, em consonância com o que ocorreu nas políticas educacionais a partir dos anos 1980, a avaliação dos sistemas públicos de ensino foi implementada no Brasil como mecanismo privilegiado de promoção da qualidade do ensino. 
Sobre essas iniciativas, a autora revela que a tônica recaiu na avaliação em larga escala, voltada para a verificação do desempenho dos alunos, sendo seus resultados interpretados como evidência da qualidade do ensino de um dado sistema, de uma dada rede ou escola. Ademais, esse tipo de avaliação é caracterizado pela ênfase nos produtos ou resultados; atribuição de mérito a alunos, instituições ou redes de ensino; dados de desempenho escalonados, resultando em classificação; dados predominantemente quantitativos; e destaque à avaliação externa, não articulada à autoavaliação.

Para a autora, o princípio adotado é o de que a avaliação gera competição, e a competição gera qualidade. Nesta perspectiva, o Estado assume a função de estimular a produção dessa qualidade, formulando políticas educacionais sob os auspícios da classificação e seleção, que, consequentemente, incorporam a exclusão como inerente aos seus resultados.

Baseadas nesta concepção, as ações de responsabilização têm provocado, nos diferentes países, forte resistência por parte das entidades de classe, de acordo com Silveira (2009). Como exemplo, o autor cita que, nos Estados de São Paulo e do Rio Janeiro, o pagamento de bônus tem levado as entidades a questionar os critérios utilizados, entre outros, o absenteísmo dos profissionais da escola, a não incorporação do bônus ao piso salarial e, ainda, o fato de os inativos serem excluídos desse pagamento. A estes, soma-se um argumento contrário a essa concepção: a escola não pode ser responsabilizada por seus resultados se 0 Estado, por meio dos ministérios e secretarias de educação, não garantirem as condições indispensáveis para um trabalho de qualidade.

Do mesmo modo, o referido autor afirma que os estudos e as experiências de avaliação com responsabilização têm sido pouco disseminados no Brasil, em decorrência de três fatores. 0 primeiro fator se refere à noção incipiente da importância do uso dos resultados da aprendizagem cognitiva e avaliação de desempenho dos alunos como peça fundamental de políticas de melhoria da qualidade educacional em médio e longo prazo. Em seguida, às carreiras do magistério, que, ao assegurarem aos docentes e demais funcionários uma quantidade significativa de faltas abonadas, tornam as políticas que utilizam critérios de frequência a serem encaradas como um descumprimento de um direito adquirido. Em terceiro lugar, à indefinição sobre o papel e a responsabilização tanto dos órgãos intermediários quanto dos ministérios e secretarias de educação no processo de melhoria da qualidade da educação, uma vez que o discurso atual tem sido o de responsabilizar unicamente diretores e professores pelo desempenho insuficiente das escolas e de seus alunos em provas nacionais ou estaduais. Nesta última, o autor considera que o posicionamento político de responsabilizar e exigir prestação de contas dos níveis intermediários de poder e do próprio executivo em comando dificilmente ocorre, o que parece denotar falta de compromisso com a efetiva melhoria da qualidade e garantia da equidade em educação.

Como se pode observar, as políticas de responsabilização, além de produzirem 
efeitos sobre os processos avaliativos dos sistemas educacionais, também influenciam no processo de profissionalização docente quando passam a estabelecer padrões avaliativos de desempenho docente. Assim sendo, Sousa (2009) declara que este sentido tem impulsionado iniciativas de vinculação de seus resultados a incentivos e que, no caso brasileiro, as evidências indicam que a tendência é caminharmos para o uso dos resultados das avaliações na perspectiva de responsabilização.

Todavia, Jesus (2009) pondera que, apesar de a avaliação do desempenho docente ser encarada como mais um fator de mal-estar dos professores, esta pode constituir um meio para o bem-estar docente, na medida em que uma autoavaliação mais elevada do desempenho do professor relacione-se significativamente com maior empenho profissional, maior orientação do projeto para continuar na docência, uma percepção mais positiva dos resultados profissionais, um maior nível de bem-estar e uma menor exaustão profissional. Esta autoavaliação do desempenho do professor relaciona-se, de forma significativa, também com a avaliação feita pelos alunos e pelos diretores.

Desta forma, Jesus (2009) acredita que a avaliação do desempenho dos professores pode constituir-se em instrumento para a qualidade escolar, para a motivação e o bem-estar docente, além de servir para diagnosticar aspectos que permitam a esse professor melhorar as estratégias para o seu desenvolvimento profissional e refletir sobre sua prática de forma construtiva. Ao desenvolver o autoconhecimento, a avaliação do desempenho pode contribuir para a maior motivação à aprendizagem e ao desenvolvimento profissional do professor.

Neste sentido, o desenvolvimento profissional compreende um processo, individual e coletivo, de construção do "eu" profissional (Marcelo, 1999). Este processo é influenciado pela escola, pelas reformas e contextos políticos, associado também às crenças e valores sobre o processo de ensino e aprendizagem dos professores, pressupondo melhorias contínuas do fazer profissional.

Desta forma, o sistema avaliativo pode configurar-se como agente que contribui para o desenvolvimento profissional docente numa perspectiva reflexiva e transformadora, ao contrário da lógica de enquadramento da prática docente em critérios definidos externa e unilateralmente, sem a participação desse profissional. 


\section{A avaliação do desempenho docente nos sistemas educacionais estaduais brasileiros}

Para este trabalho, fizemos o levantamento nas 27 Secretarias de Estado da Educação ${ }^{1}$ dos 26 estados e do Distrito Federal, por meio das informações disponíveis nos seus sítios. A primeira informação que buscamos foi se o estado possuía processos de avaliação de desempenho docente, quais os seus objetivos e se essa avaliação estava vinculada ao desempenho dos alunos nos processos avaliativos nacionais ou locais. Dessa forma, consideramos para análise somente os estados que possuem tais processos. Buscamos, ainda, entender se essas avaliações estavam voltadas para o desempenho profissional e progressão na carreira ou se o mote era a bonificação pelos resultados alcançados pelos professores e/ou alunos nas avaliações.

Por meio do levantamento de dados, foi possível observar que em quatro dos sete Estados da Região Norte (Amazonas, Acre, Roraima e Tocantins) existem políticas voltadas à avaliação de desempenho. No Estado do Amazonas, a Secretaria de Estado da Educação e Qualidade do Ensino estabelece no Plano Plurianual (PPA) 2012-2015 a Política de Valorização de Profissionais da Educação, com a formação inicial e continuada dos servidores da educação da capital e do interior nas diversas áreas do conhecimento, com diversas premiações de incentivo à melhoria da educação.

A política denominada Premiação por Mérito do Desempenho Educacional foi criada pelo Governo do Estado do Amazonas e objetiva, segundo o PPA, garantir o acesso da população amazonense à educação e ao conhecimento com equidade, qualidade e valorização da diversidade, elevando-se o Índice de Desenvolvimento da Educação Básica ${ }^{2}$ (Ideb), no segmento das escolas estaduais, melhorando a qualidade do ensino fundamental; expandir e qualificar o ensino médio, atendendo também à demanda da zona rural do Estado.

A política estabelece prêmios aos profissionais das escolas que atingem as metas preestabelecidas pela Secretaria, como o pagamento do $14^{\circ}$ e $15^{\circ}$ salários. Essas metas são influenciadas pelos resultados de mecanismos de avaliação de

1. Vale ressaltar que o Brasil é organizado de forma federativa e o seu sistema de ensino está subdivido entre os entes federados, a saber: União, estados e municípios. Assim, além das instituiç̃ões de educação superior que compõe o sistema federal de educação, a educação básica está organizada e sob a responsabilidade dos 26 estados e do Distrito Federal, que formam os sistemas estaduais de educação e dos 5.565 municípios, sendo que cada um deles possui sistema próprio. Isso significa que temos 5.592 sistemas de ensino para atender a educação básica.

2. A educação básica no Brasil é composta por três etapas: educação infantil (de zero a cinco anos de idade), ensino fundamental (de seis a catorze anos) e ensino médio (de quinze a dezessete anos). Além das etapas, existem ainda algumas modalidades, como educação de jovens e adultos, educação profissional, educação indígena, educação especial, educação do campo, entre outras. 
desempenho de alunos - Índice do Desenvolvimento da Educação Básica (ldeb) e Índice do Desenvolvimento da Educação no Amazonas (Ideam) -, indicados como reflexos das ações dos programas que formam o eixo estratégico do sistema estadual de ensino público.

Assim, compreende-se que a concepção que orienta a política se dá na perspectiva de responsabilização do professor, fundamentada nos resultados do desempenho do aluno, promovendo um processo de bonificação que não contribui para o desenvolvimento da carreira docente.

No Acre, o Decreto n 5.592/2010, de 15 de agosto de 2010, instituiu o Prêmio Anual de Valorização e Desenvolvimento Profissional (PAVDP), que consiste em uma avaliação voluntária e que integra a política de valorização de pessoal do Governo do Estado e objetiva premiar os professores da Secretaria de Estado de Educação do Acre, tendo como critérios o cumprimento da jornada escolar dentro do calendário letivo, a participação nos programas de formação continuada oferecidos pela SEE e o cumprimento das horas de atividades previstas no planejamento da unidade de ensino.

0 prêmio contempla o resultado individual de cada professor, com periodicidade mínima de um semestre, não se incorporando aos vencimentos nem servindo de base de cálculo dos proventos de aposentadoria.

Analisando-se esta política, depreende-se que a concepção que a orienta também se dá na perspectiva de responsabilização do professor, promovendo um processo de bonificação que não contribui, explicitamente, para o desenvolvimento da carreira docente. Diferentemente da política do Estado do Amazonas, a política do Estado do Acre não se fundamenta nos resultados do desempenho do aluno, apesar da existência do Sistema Estadual de Avaliação da Aprendizagem Escolar (Seape), mas no cumprimento de metas estabelecidas pelo sistema estadual.

Em Roraima, o regulamento do Prêmio Professor Excelência tem como objetivos: valorizar o professor como principal agente no processo de melhoria da qualidade do ensino; premiar os professores da rede pública estadual de ensino; reconhecer, pelos resultados da sua prática junto às crianças, a relevância do trabalho dos professores da educação básica como intervenção transformadora; promover o debate e a troca de informação sobre o conhecimento pedagógico; divulgar experiências educativas de qualidade, planejadas e executadas nas escolas de ensino regular, superando as dificuldades do dia a dia.

Com esses objetivos, a política estadual prevê a premiação de dois professores em exercício, lotados nas escolas estaduais da rede pública de ensino, sendo um professor representante da educação infantil ${ }^{3}$ e $1^{\mathrm{a}}$ a $4^{\mathrm{a}}$ séries, e outro professor

3. Apesar da Lei $9.394 / 96$ determinar a oferta da educação infantil e ensino fundamental aos municípios, é possível que a premiação considere um trabalho conjunto entre Estado e municípios, no sentido da melhoria dos índices educacionais ou mesma da oferta. 
representante da $5^{a}$ a $8^{a}$ séries e ensino médio, por meio da avaliação do desempenho dos professores e projetos desenvolvidos na escola.

Os dois Professores Excelência do Estado de Roraima receberão como premiação uma viagem para a Europa, o Diploma de Honra ao Mérito e a edição de um livro com o relato das experiências desenvolvidas nas escolas. Os professores que obtiverem o $2^{\circ}$ e $3^{\circ}$ lugar de cada categoria receberão como premiação um notebook.

Sobre esta política, percebe-se que a concepção que a orienta, da mesma forma que as anteriores, dá-se na perspectiva de responsabilização do professor, promovendo um processo de bonificação desvinculado da carreira docente. Também não se fundamenta nos resultados do desempenho do aluno, mas no atendimento a critérios de avaliação de projetos e relatórios estabelecidos pela comissão de avaliação.

Já no Estado de Tocantins, o Edital n 1/2011 instituiu o Prêmio de Valorização da Educação Pública do Tocantins. Esta política objetiva incentivar, por meio de prêmios definidos por categorias, os bons desempenhos das Diretorias Regionais de Ensino, unidades escolares, professores regentes e alunos regularmente matriculados no $5^{\circ}$ e $9^{\circ}$ ano do ensino fundamental e no $3^{\circ}$ ano do ensino médio no Sistema de Avaliação do Tocantins (Salto) e no Ideb, objetivando estimular a gestão e as práticas educativas que, direta ou indiretamente, subsidiam a boa qualidade das aprendizagens e o sucesso dos educandos nas avaliações e ingresso nas instituições de ensino superior.

Para cada categoria, são concedidas as seguintes premiações:

- Categoria Diretoria Regional de Ensino: viagem de estudos a uma cidade brasileira que esteja sediando congresso ou seminário educacional de efetiva qualidade técnica, como Sociedade Brasileira para o Progresso da Ciência (SPBC), Encontro Nacional de Didática e Práticas de Ensino (Endipe), etc., com duração de até uma semana, incluindo despesas com locomoção, estadia e passagens para o gestor da DRE e até trinta membros da equipe da Diretoria Regional de Ensino lescolhidos pelos critérios de assiduidade, produtividade e dinamismol que apresentar a maior média entre as DRE na avaliação do Salto;

- Categoria Unidade Educacional: premiação em dinheiro no valor de dez mil reais para cada uma das cem escolas públicas estaduais que obtiverem os melhores resultados no Sistema de Avaliação do Tocantins (Salto), podendo ser utilizado para reforma, ampliação e/ou aquisição de equipamentos;

- Categoria Profissionais da Educação: o valor de mil reais para cada professor regente, coordenador pedagógico, orientador educacional e gestor escolar, e duzentos reais para os demais servidores das cinquenta escolas públicas estaduais que obtiverem os melhores resultados no Salto;

- Categoria Índice de Desenvolvimento da Educação (Ideb): o valor de três mil reais para cada professor regente, coordenador pedagógico, orientador educacional e gestor escolar, e oitocentos reais para os demais servidores de todas as 
escolas estaduais que atingirem índice igual ou superior a 6,0 no Ideb; caso a unidade educacional alcance o índice 6,0 em mais de uma etapa de ensino, o prêmio não será cumulativo;

- Categoria Educandos: seis mil unidades de tablets para os alunos da Rede Estadual que obtiverem os melhores resultados no Sistema de Avaliação do Tocantins (Salto).

- Categoria Profissionais da Educação Municipal: um notebook aos professores de Língua Portuguesa e Matemática das escolas municipais que atingirem índice igual ou superior a 6,0 no Ideb, até o limite de cem escolas.

- Categoria Técnico da Secretaria de Educação (Seduc): viagem de estudos a uma cidade brasileira que esteja sediando congresso ou seminário educacional de efetiva qualidade técnica, como o SPBC, Endipe, etc. com duração de até uma semana, incluindo despesas com locomoção, estadia e passagens para até 30 servidores da Seduc que tenham se destacado em atividades/projetos exitosos.

No Tocantins, a concepção evidenciada na orientação da política também é direcionada na perspectiva de responsabilização do professor e dos demais sujeitos envolvidos no sistema, promovendo um processo de bonificação desvinculado da carreira docente e sendo fundamentada nos resultados do desempenho do aluno, por meio do Salto e do Ideb.

Na Região Nordeste, que conta com o maior número de Estados da Federação (Alagoas, Bahia, Ceará, Maranhão, Paraíba, Pernambuco, Piauí, Rio Grande do Norte e Sergipe), não foram identificados processos de avaliação em Alagoas, no Maranhão e no Piauí.

0 Estado da Paraíba instituiu o Prêmio Educação Exemplar, por meio da Medida Provisória $n^{0} 181$, de 22 de agosto de 2011. O prêmio se configura em edital público dirigido aos profissionais em exercício nas escolas públicas estaduais de educação básica e tem os seguintes objetivos: fomentar, selecionar, valorizar e premiar as melhores práticas pedagógicas, com ações integradas e métodos docentes planejados e executadas por profissionais de educação, cujo foco é o atendimento aos desafios encontrados para a melhoria dos processos de ensinoaprendizagem.

0 edital traz um exaustivo detalhamento dos critérios de participação tanto da categoria Escola como da categoria Professores. No geral, esses critérios estão atrelados: al ao desempenho, no ano anterior à vigência do prêmio, nas avaliações externas (Ideb, Enem, Prova Brasil), com $80 \%$ de participação dos professores da escola em ações de formação continuada; b) à adequada apresentação da prestação de contas, bem como a participação em outros programas implementados pela rede de ensino. Para os professores, a exigência é a apresentação de uma autoavaliação, um relato que contemple pelo menos dois eixos norteadores da proposta pedagógica do Estado, com a comprovação tanto da participação de $80 \%$ dos alunos na experiência relatada quanto da participação do professor em $80 \%$ das 
ações de formação continuada. Após a inscrição no prêmio, o candidato aguarda duas etapas posteriores: a indicação da aprovação do seu relato, a ser submetido a avaliação; a classificação do trabalho, a ser avaliado por banca constituída para esse fim específico.

0 valor do prêmio corresponde a uma remuneração mensal, porém não se deixa claro se esta seria referente apenas ao valor dos vencimentos ou agregaria possíveis gratificações existentes.

Desta forma, verifica-se que a política se mostra atrelada ao desempenho de alunos em índices externos, não sendo identificada a reflexão do professor de como estes resultados contribuem para o seu efetivo desenvolvimento profissional, tendo em vista que o relato apresentado tem como finalidade a prestação de contas das metas determinadas pelo sistema avaliativo. Por outro lado, a premiação é ocasional, configurando-se como prática distante da valorização docente.

No Estado de Pernambuco, foi estabelecido, desde 2007, um sistema de bonificação alinhado à Lei de Responsabilidade Educacional, Lei n 13.273/2007, que denota claramente que esta unidade federada aderiu a uma política de responsabilização pautada na instituição de metas e implantação de um indicador local - Índice de Desempenho da Educação de Pernambuco (Idepe), além de agregar o desempenho nos resultados do sistema de avaliação local, o Sistema de Avaliação Educacional de Pernambuco (Saepe). A avaliação e bonificação docente acontecem de forma indireta, pois é a unidade escolar que, ao atingir pelo menos $50 \%$ da meta estabelecida para a projeção do indicador local, torna professores e demais funcionários aptos a receber a bonificação.

Essa bonificação não atinge o sistema de forma global, pois as escolas da rede que não tiveram matrícula nas antigas $4^{\circ}$ e $8^{a}$ séries e no $3^{\circ}$ ano do ensino médio não podem pleitear a bonificação. Ela é estendida ainda para as regionais de ensino cujas escolas jurisdicionadas tenham alcançado $50 \%$ da meta estabelecida. Nesse sentido, foi estabelecido um sistema de monitoramento pelas regionais. A remuneração recebida pode ultrapassar o valor de uma remuneração mensal, podendo os profissionais das escolas e das regionais de ensino receberem o equivalente ao atingimento de $100 \%$ da meta estabelecida. Porém, essa remuneração não é incorporada aos salários dos docentes.

A política desenvolvida em Pernambuco parece acentuar uma lógica de controle do trabalho pedagógico da escola e dos docentes, na mesma direção que a política de Paraíba orienta. Apesar de este Estado desenvolver seu próprio índice, a lógica de responsabilização orienta-se na direção das diretrizes de avaliação do desempenho docente, sendo a premiação pelo alcance das metas também ocasional, sem impacto remuneratório na carreira.

No Estado da Bahia, desde 2009 foi implementado um sistema de avaliação de desempenho docente cujo objetivo é fomentar políticas de formação continuada com impacto remuneratório no plano de cargos e carreira. Tal avaliação é desenvolvida por meio da adesão voluntária do professor à submissão de uma 
prova de conhecimentos gerais e específicos. A progressão na carreira será concedida proporcionalmente ao número de inscritos em cada disciplina, dentro do limite de 3.000 vagas, e os candidatos são classificados em ordem decrescente, a partir das maiores notas obtidas, após se ultrapassar um ponto de corte.

Esse último mecanismo desvela um caráter classificatório e meritocrático da avaliação instituída, porém é válido ressaltar que a Bahia foi o único Estado da Região Nordeste que não aderiu a um sistema de premiação direta ou indireta, e o modelo adotado pode abrir vias de uma análise mais aprofundada do papel da avaliação com um caráter mais formativo, uma vez que agrega ao instrumento a iniciativa de fomentar políticas de formação continuada mediante o estudo do desempenho geral dos professores participantes da avaliação. Além disso, inserese nos critérios de progressão funcional, tendo rebatimento para a estruturação da carreira dos docentes, mesmo que de forma limitada, quando define um número mínimo de professores que podem progredir a partir do desempenho na avaliação realizada.

0 Estado do Ceará instituiu desde 2009, por meio da Lei nº 14.484/09, o Prêmio Aprender para Valer. 0 prêmio tem caráter meritocrático, uma vez que é apontado claramente na lei de implantação que um dos seus objetivos é reconhecer o mérito das escolas que tenham alcançado as metas anuais de evolução da aprendizagem dos alunos. A avaliação docente é desenvolvida em duas etapas: a primeira, por meio de prova individual de conhecimentos específicos e pedagógicos; a segunda, por meio da avaliação institucional. Serão classificados os participantes que obtiverem um indicador igual a sessenta pontos. Esse indicador é baseado nas metas que são estabelecidas anualmente pelo Executivo e que servem de critério para que a escola se submeta ao prêmio. Tais metas têm ainda como referência os resultados do Sistema Permanente de Avaliação da Educação Básica (Spaece).

Além desses aspectos, o cálculo para o recebimento da premiação é estabelecido por meio do índice mínimo de 70\%, quando ocorrer pelo menos um acréscimo de $7 \%$ na média de proficiência dos alunos no referido sistema; e do índice máximo de $100 \%$, quando o acréscimo do desempenho dos alunos no exame do Spaece for $10 \%$ ou mais. Esse acréscimo terá como referência a avaliação no Spaece do ano de referência, no caso o ano de 2009.

Vê-se novamente, no caso do Estado do Ceará, um rebuscamento nos critérios e cálculos correspondentes para a premiação, sendo que esses podem apresentarse muito mais como desestímulo do que fomento para um adequado processo de desenvolvimento profissional docente.

No caso do Rio Grande do Norte, em 2006, foi promulgada a Lei Complementar $n^{\circ} 322 / 2006$, que regulamenta o plano de cargos, carreira e remuneração do magistério público estadual do Rio Grande do Norte. Em relação à progressão funcional, tal lei aponta como elemento decisivo a avaliação de desempenho, e não mais o tempo de serviço, como ocorria anteriormente. Essa avaliação deveria ser estabelecida com base em normas elaboradas pela Comissão de Gestão do Plano 
de Cargos, Carreira e Remuneração do Magistério Público Estadual, porém a comissão nunca foi constituída, conforme destacam Ferreira e Oliveira (2011). No texto da lei, os requisitos gerais para o estabelecimento de critérios, pontuações e/ou menções correspondentes são:

I - desempenho das funções de magistério;

II - produção intelectual;

III - qualificação profissional; e,

IV - rendimento obtido pelos alunos da Unidade de Ensino em que o Professor ou Especialista de Educação for lotado

Aquela comissão iria avaliar os relatórios preenchidos pelos próprios professores e especialistas de educação, conforme a pontuação estabelecida. Sem a comissão instituída, o único procedimento vigente para a progressão horizontal permaneceu sendo o do registro da titulação.

Percebe-se, portanto, que não houve avanços no sistema de avaliação do Rio Grande do Norte, sendo que este somente privilegia a progressão por titulação. Desta forma, não foi possível identificar mecanismos de responsabilização relacionados ao desempenho de alunos, nem outros critérios que abordem a atuação profissional do docente em exercício. Assim, a ênfase do desenvolvimento profissional é reduzida à formação acadêmica.

Em 2004, o Estado de Sergipe, por meio da Lei no 5383/2004, instituiu o Sistema de Avaliação Periódica de Desempenho (Saped) do profissional do magistério, implementando a Gratificação Variável de Desempenho (GRAVAD). A Lei não deixa claros os critérios para que os profissionais façam jus à gratificação, indicando apenas que será o Executivo quem definirá os critérios. São submetidos a tal avaliação periódica, de acordo com a referida lei: al professores de educação básica e pedagogos do magistério público estadual atuando na educação infantil, no fundamental e nível médio de ensino, e respectivas modalidades, em efetiva regência de classe ou atividade de turma nos estabelecimentos de ensino ou unidades escolares da rede pública estadual de ensino; b) alunos da rede pública estadual de ensino, nos diversos componentes curriculares; cl equipes gestoras dos estabelecimentos de ensino ou unidades escolares da rede pública estadual de ensino. Não conseguimos identificar nenhum relato sobre as repercussões deste sistema de avaliação de desempenho docente, nem por quanto tempo esteve vigente.

Em 2011, já sob outra gestão, uma proposta de avaliação de desempenho denominada de Índice Guia foi implementada. Segundo a proposta, as escolas precisam assumir o compromisso de atingir as metas definidas pelos gestores da Secretaria de Educação, sendo passíveis de diversas punições, inclusive a demissão da equipe diretora e dos professores. As metas definidas estão atreladas aos resultados das provas externas (Prova Brasil, Provinha Brasil e Enem) e não estão articuladas a nenhuma outra ação que tenha impacto com o desenvolvimento profissional docente. Além desses aspectos, a construção do índice está baseada 
num modelo pedagógico que estabelece a rotulação de alunos "atrasados" e "avançados" e a classificação de professores de "excelência" e professores "insuficientes". Esse modelo é pautado pela elaboração de portfólio individual do aluno e por uma pontuação correspondente à quantidade de atendimento com aulas de reforço escolar que o professor pode ministrar no contraturno, entre outros aspectos. A predominância, então, é de uma lógica punitiva e quantitativa para as unidades escolares e seus professores, sendo bastante criticada pelo sindicato dos profissionais da educação daquele Estado.

A Região Sudeste do País, composta por quatro Estados (Espírito Santos, Minas Gerais, Rio de Janeiro e São Paulo), também apresenta programas de avaliação de desempenho ou processo de bonificação baseados nos resultados obtidos pelos alunos nas avaliações.

No Estado de São Paulo (SP), a Lei Complementar n 1.097, de 27 de outubro de 2009, instituiu o Sistema de Promoção para os Integrantes do Quadro do Magistério da Secretaria da Educação. De acordo com este sistema, a remuneração foi dividida em cinco faixas. Para cada faixa, o educador precisa atingir uma nota mínima em prova aplicada pela secretaria. 0 interstício que o professor precisa cumprir entre uma progressão e outra é de pelo menos quatro anos, e os ganhos obtidos nesse sistema de progressão funcional é incorporado à aposentadoria do servidor. Para - educador alcançar a quinta faixa salarial e alcançar um aumento de $100 \%$ no salário, ele precisa obter nove pontos na avaliação e ter ao menos 16 anos de profissão.

O Estado de SP também conta com um sistema de avaliação de alunos, o qual é utilizado para bonificação, que é diferente da progressão funcional. 0 bônus pode chegar, a cada ano, a até $25 \%$ do salário do professor. Dessa forma, se o professor está lotado e trabalhando em uma escola que supera as metas todos os anos, ele ganha $25 \%$ a mais de seu salário anualmente, mas esse ganho não é somado à aposentadoria.

Considerando a política adotada por este Estado, verifica-se um misto de dois tipos de avaliação: de alunos e de professores, bem como uma política de progressão funcional e uma de bonificação para os professores com base no alcance de metas por parte das escolas. Analisando essas políticas, percebe-se um alinhamento com o que vem sendo praticado por outros estados, no que se refere à bonificação; e uma inovação, no que se refere ao sistema de progressão funcional, uma vez que esse tipo de sistema ainda é raro nos estados brasileiros. Não obstante a existência de uma legislação voltada para a progressão dos quadros do magistério, ainda é preocupante a forma como essa progressão se dá, mediante, basicamente, provas de desempenho, sem considerar o trabalho docente.

No Estado do Rio de Janeiro (RJ), o Decreto n 42.793, de 6 de janeiro de 2011, estabeleceu programas para o aprimoramento e a valorização dos servidores públicos da secretaria de educação. De acordo com o decreto, é estabelecido um sistema de bonificação com base na avaliação anual dos alunos da rede estadual. 
Essa avaliação considera o resultado dos alunos em provas de língua portuguesa e matemática, bem como os dados referentes ao fluxo escolar. Cada escola possui uma meta a atingir, a cada ano, e a bonificação é paga de acordo com a função do servidor, sua carga horária e o percentual de atingimento das metas estabelecidas para a escola, sendo calculada sobre o vencimento base do servidor. Vale ressaltar que essa bonificação não é incorporada aos vencimentos, salários, proventos ou pensões. Ela é concedida em parcela única, no ano subsequente à avaliação, para os servidores lotados em escolas que cumpriram as metas estabelecidas.

Analisando essa política praticada pelo Estado do RJ, muito comum em outros estados brasileiros, responsabiliza-se o docente e/ou a equipe escolar pelos resultados dos alunos, sendo que muitas outras variáveis também contribuem para os resultados escolares, as quais não são passíveis de mudança por parte da escola.

O Estado de Minas Gerais instituiu uma gestão administrativa com foco no controle das ações e gerenciamento do desempenho dos servidores, que são diretrizes fundamentais do projeto Choque de Gestão. E alinhada com esse projeto está a Avaliação de Desempenho Individual (ADI), composta por critérios de julgamento com caráter avaliativo e punitivo (Alves, 2006). Esta avaliação considera, entre outros, produtividade no trabalho, iniciativa, aproveitamento em programas de capacitação, pontualidade e assiduidade.

Ao avaliar essa política, pode-se destacar como ponto positivo o fato de não ser apenas um sistema de bonificação, mas de progressão funcional, e o uso de critérios não atrelados ao cumprimento de metas de desempenho dos alunos. Todavia, como indica Alves (2006), esse sistema pode prejudicar direitos adquiridos pelos servidores, ao ser substituído o tempo de serviço pelo desempenho individual para o cálculo dos adicionais. Ressalte-se, também, que a avaliação por pares tem fragilidades, tais como interferências pessoais e de amizade.

No Estado do Espírito Santo, há um projeto de lei aprovado pela Assembleia Legislativa que prevê uma gratificação para os educadores chamada Bônus Desempenho. Trata-se de prêmio em dinheiro, concedido uma vez por ano, que pode chegar até o valor de um salário a mais por ano, dependendo do resultado da unidade escolar. Os critérios utilizados para a concessão do bônus são: desempenho dos alunos no Programa de Avaliação da Educação Básica do Espírito Santo (Paebes), fluxo escolar e frequência do professor.

Mais uma vez, em consonância com o que é praticado em outros Estados, o Espírito Santo também atrela um sistema de bonificação ao desempenho dos alunos. Ademais, trata-se apenas de um sistema de bonificação, sem qualquer ligação com o plano de carreira docente.

Na Região Centro-Oeste, formada pelos Estados de Goiás, Mato Grosso, Mato Grosso do Sul e Distrito Federal, não foi possível identificar nenhuma unidade federada que tivesse uma política explícita de avaliação de desempenho docente baseado no processo de desenvolvimento profissional e progressão na carreira, 
com exceção do Estado de Goiás, que possui um programa explícito de bonificação docente, o Programa Reconhecer - Estímulo à Regência. Esse programa é voltado para a bonificação de assiduidade: entre as condições para que a Secretaria de Estado da Educação faça o pagamento do benefício, a ficha de frequência dos professores deve ter sido afixada nos murais das escolas. 0 bônus, de no máximo $\mathrm{R} \$ 1.500$, será pago aos professores em regime de 40 horas de trabalho semanal, sendo proporcional aos que tiverem cargas horárias diferentes e ao número de faltas do professor no semestre.

Percebe-se, assim, que a política de bonificação valoriza apenas uma dimensão da atuação docente, a da frequência, o que a torna superficial e insuficiente no que se refere ao entendimento do desenvolvimento profissional docente. Além disso, a frequência é um dos deveres do professor que, no entendimento da política, é premiado por cumprir aquilo que já é esperado dele, ao mesmo tempo em que é punido quando deixa de receber a premiação.

O levantamento da Região Sul apontou que o Estado do Rio Grande do Sul, apesar das avaliações dos estudantes em curso e das discussões que vêm sendo feitas para alterar o regulamento da promoção do magistério público estadual, o que está em voga ainda é o Decreto n⿳0 34.823, de 2 de agosto de 1993, que define as normas para progressão na carreira dos docentes da rede pública desse Estado.

No Estado de Santa Catarina, não foi identificado nenhum programa de avaliação de desempenho.

No Paraná, foi identificado o Programa de Desenvolvimento Educacional (PDE), que tem como objetivo fazer com que os professores da rede pública estadual desenvolvam, por meio de processos de formação continuada, subsídios teóricometodológicos para o desenvolvimento de ações educacionais sistematizadas, que resultem em redimensionamento de sua prática.

Pelos dados levantados, foi possível identificar que, das 27 Secretarias de Estado de Educação pesquisadas, 16 possuem processos de avaliação de desempenho, sendo que a maioria objetiva, em última instância, oferecer bonificação aos professores, seja pelo critério do desempenho de alunos, seja pelos resultados alcançados pelas escolas no atingimento de metas estabelecidas pelas próprias Secretarias. Por outro lado, alguns estados não possuem sistemas de avaliação de desempenho docente, mas também usam os resultados das avaliações dos alunos para bonificar seus professores.

\section{Considerações finais}

Diante do exposto, observamos que nos estados brasileiros há em curso uma política de avaliação docente na perspectiva da responsabilização, confirmando a proposição de Sousa (2009). Seja como política indutora com adesão voluntária 
para concorrer a premiações, seja como monitoramento contínuo das ações para o alcance de metas instituídas pelo Executivo, a avaliação docente está submetida a uma lógica de responsabilização.

Em todos os casos, tanto na adesão a determinado prêmio quanto na instituição do sistema de bonificação, o caráter remuneratório é pontual, provisório e condicionado, não incidindo nos cálculos dos vencimentos e gratificações que integram os salários dos professores. Além desse aspecto, ao analisar as políticas de responsabilização dos estados brasileiros, observa-se um rebuscamento dos critérios, criados de forma unilateral pela pasta executiva do Estado, o que, em si, fere um princípio de desenvolvimento profissional segundo o qual os sujeitos deveriam ter participação mais ativa, o que contribuiria para a intensificação do trabalho docente. Gera ainda um sistema de competição, o que não contribui para a melhoria da qualidade da educação. Ademais, comenta-se que muitos desses critérios parecem alimentar uma lógica quantitativista no que se refere à participação em ações de formação continuada, em detrimento de uma sólida política de desenvolvimento profissional docente. Tal política se distanciaria de uma compreensão reducionista do desenvolvimento, que apenas justapõe a formação inicial e continuada pela ótica do déficit, embasando uma concepção formativa da avaliação.

Por fim, percebe-se, ainda, que os sistemas de avaliação implementados pouco ou quase nada se relacionam aos demais elementos de desenvolvimento profissional e valorização docente, a saber: o direito à formação continuada, à melhoria de condições de trabalho e principalmente, como já foi destacado anteriormente, à adequada remuneração para a função social exercida.

Ao mesmo tempo, a incipiência de estudos que comprovem a relação dessas políticas com a melhoria da qualidade educacional nos sistemas estaduais nos dão a dimensão da necessidade de profundas reflexões acerca das reformas educacionais implementadas, suas proposições e políticas subjacentes, pois, pelos avanços educacionais tão discretos que temos observado ao longo dos anos, não parece que a política de responsabilização em vigor, com o uso de prêmios e bonificações, esteja surtindo os efeitos desejados. Dessa forma, é necessário que se avalie o uso dessa política e se analise se é a mais adequada para o contexto educacional brasileiro.

\section{REFERÊNCIAS}

ACRE. Decreto n 5.592/2010, de 16 de agosto de 2010. Institui o Prêmio Anual de Valorização e Desenvolvimento Profissional - PAVDP. Disponível em: <www. sinplac.dominiotemporario.com/doc/PAVDP-VDP.docx>. Acesso: 11 jul. 2012.

AKKARI, Abdeljalil. Internacionalização das políticas educacionais: transformações 
e desafios. Petrópolis: Vozes, 2011.

ALVES, Ana Carolina Timo. As reformas em minas gerais: choque de gestão, avaliação de desempenho e alterações no trabalho docente. Trabalho apresentado em: VI Seminário da Redestrado - Regulação educacional e trabalho docente, novembro de 2006, UERJ: Rio de Janeiro.

AMAZONAS. Seplan. Plano Plurianual. PPA 2012 - 2015. Disponível em: <www. seplan.am.gov.br/.../20110720095928apresentacao_ppa.pdf>. Acesso em: 11 jul. 2012.

BROOKE, Nigel. 0 futuro das políticas de responsabilização educacional no Brasil. Cadernos de Pesquisa, v. 36, n. 128, mai/ago, 2006. p. 377-401.

DEE, Thomas S. A primeira onda de responsabilização. In: BROOKE, Nigel. Marcos históricos na reforma da educação. Belo Horizonte: Fino Traço, 2012. p. 157 - 162.

FERNANDES, Domingo. Avaliação do desempenho docente: desafios, problemas e oportunidades. Portugal: Texto Editores. Disponível em: <http:// www.cesgranrio. org.br>. Acesso em: 19 ago. 2010.

FERREIRA, Maria Aparecida dos Santos; OLIVEIRA, Edmilson Jovino de. Financiamento da educação básica e valorização docente: um estudo do PCCR da rede pública estadual do RN. In: Anais do $25^{\circ}$ Simpósio Brasileiro e $2^{\circ}$ Congresso Ibero-Americano de Política e Administração da Educação. São Paulo: Anpae, 2011.

GOIÁS, Programa de Estímulo à Regência - Reconhecer, 2011.

JESUS, Saul Neves de. A avaliação dos professores como processo de desenvolvimento pessoal e profissional. In: MELO, Marcos Muniz (Org). Avaliação na educação. Pinhais: Editora Melo, 2007.

MARCELO, Carlos. Desenvolvimento profissional docente: passado e futuro. SìSIFO/Revista de Ciências da Educação. Lisboa, n. 8, jan/abr, 2009. p. 7-22.

NEUBAUER, Rose; SILVEIRA, Ghisleine Trigo. Gestão dos sistemas escolares - quais caminhos perseguir? In: SCHWARTZMAN, Simon; COX, Cristián (Orgs). Políticas educacionais e coesão social: uma agenda latino-americana. Rio de Janeiro: Elsevier; São Paulo: IFHC, 2009.

PARANÁ. Lei Complementar n 103, de 15 de março de 2004. Institui e dispõe sobre o Plano de Carreira do Professor da Rede Estadual de Educação Básica do Paraná e adota outras providências. Disponível em: <http://www.legislacao.pr.gov. $\mathrm{br} /$ legislacao/pesquisarAto.do?action=exibir \&codAto $=7470 \&$ codltemAto=63745 $>$. Acesso em: 11 jul. 2012.

RIO GRANDE DO NORTE. Lei Complementar n 322/06, de 05 de dezembro de 2006. Altera a lei complementar $n^{0} 142$, de 21 de dezembro de 1998, e dá outras providências. Disponível em: <http://tj-rn.jusbrasil.com.br/legislacao/756837/leicomplementar-322-06-timbo-0>. Acesso em: 11 jul. 2012.

RIO GRANDE DO SUL. Decreto No 34.823, de 02 de agosto de 1993. Aprova novo Regulamento de Promoções do Magistério Público Estadual. Disponível em: $<$ http://www.al.rs.gov.br/legis/M010/M0100099.ASP?Hid_Tipo=TEXTO\&Hid_Toda 
sNormas $=14250 \&$ hTexto=\&Hid_IDNorma=14250>. Acesso em: 11 jul. 2012.

RORAIMA. Regulamento do Prêmio Professor Excelência. Disponível em: <http:// www.educacao.rr.gov.br/download/regulamento_premio_professor_excelencia. pdf>. Acesso em: 11 jul. 2012.

SOUSA, Sandra Zákia Lian. Avaliação e gestão da educação básica no Brasil: da competição aos incentivos. In: DOURADO, Luiz Fernandes. Políticas e Gestão da Educação no Brasil: novos marcos regulatórios? São Paulo: Xamã, 2009. (p. 31 45).

TOCANTINS. Edital 01/2011. Institui o Prêmio de Valorização da Educação Pública do Tocantins. Disponível em: <http://www.novitrine.com.br/administracao/files/ files/EDITAL\%20PROFISSIONAIS\%20DA\%20EDUCA\%C3\%87\%C3\%830.pdf> Acesso em: 11 jul. 2012

VALVERDE, Gilberto A. Padrões e avaliação. In: SCHWARTZMAN, Simon; COX, Cristián (orgs). Políticas educacionais e coesão social: uma agenda latino-americana. Rio de Janeiro: Elsevier; São Paulo: IFHC, 2009.

Recebido em agosto de 2012

Aprovado em janeiro de 2013

Danielle Xabregas Pamplona Nogueira é doutora em Educação pela Universidade de Brasília e professora do Departamento de Planejamento e Administração da Faculdade de Educação da Universidade de Brasília. Email: danielle.pamplonala gmail.com

Girlene Ribeiro de Jesus é doutora em Psicologia e professora na Faculdade de Educação da Universidade de Brasília. Email: girleneđunb.br

Shirleide Pereira da Silva Cruz é doutora em Educação pela Universidade Federal de Pernambuco (UFPE) e professora adjunta na Faculdade de Educação da Universidade de Brasília. Email: shirleidecruz@unb.br 